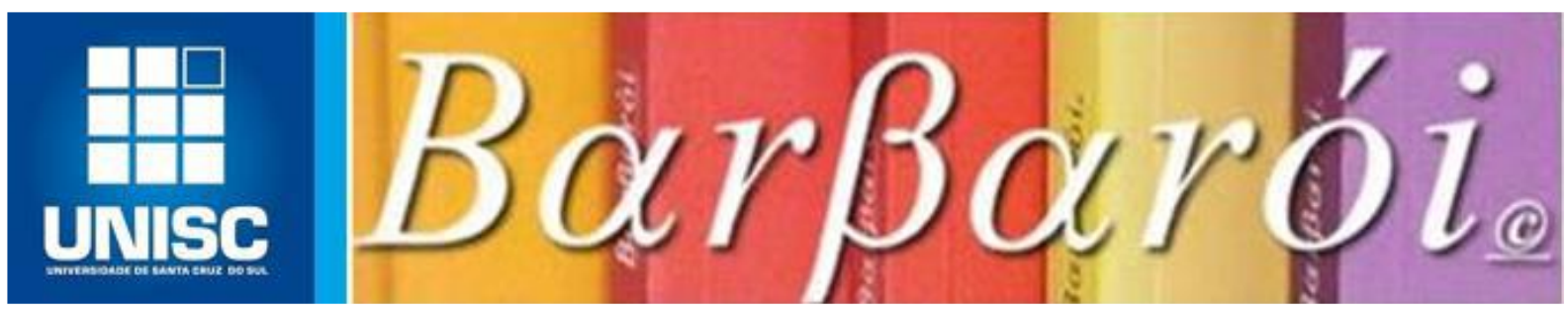

\title{
POLÍTICA NACIONAL DE SAÚDE DO TRABALHADOR E DA TRABALHADORA: UMA REFLEXÃO SOBRE A GESTÃO DA SAÚDE E DOENÇA DA CLASSE-QUE- VIVE-DO-TRABALHO
}

\author{
DOI: http://dx.doi.org/10.17058/barbaroi.v0i0.15069

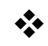

\author{
Maritânia Salete Salvi Rafagnin \\ Universidade Católica de Pelotas - UCPel - Brasil \\ Thiago Ribeiro Rafagnin \\ Universidade Federal do Oeste da Bahia - UFOB - Brasil
}

\section{Resumo}

Busca-se realizar uma discussão acerca da Política Nacional de Saúde do Trabalhador e da Trabalhadora (PNSTT), no contexto brasileiro, a partir de uma reflexão sobre o processo de saúde e doença da classe-que-vive-do-trabalho. Para tanto, parte-se do pressuposto teórico que uma política, quando delineada e implementada, pode resultar num processo duplo, produzindo por um lado, personagens sociais e por outro, estabelecendo um domínio de intervenção do Estado. A partir da análise realizada, verificou-se que no âmbito do Sistema Único de Saúde, a atuação é voltada apenas para o tratamento das doenças, invisibilizando os trabalhadores, deixando, assim, de relacionar o processo de trabalho com o adoecimento. Ademais, identificou-se que embora seja uma política com atenção ampla aos trabalhadores, no imaginário social, tem como personagem o trabalhador inserido no mercado formal, que desempenha atividades de risco relacionadas ao "trabalho pesado". Com relação aos limites de atuação do Estado, pode-se observar que agindo apenas com medidas de tratamento, não se assegura a promoção e prevenção da ST. Esse desempenho, por sua vez, leva-nos a concluir que o foco da atenção estatal parece estar direcionado, prioritariamente, para os interesses econômicos do capital.

Palavras-chave: Política Nacional de Saúde do Trabalhador e da Trabalhadora. Classe-quevive-do-trabalho. Sistema Único de Saúde.

\section{Introdução}

Homologada no ano de 2012, pela Portaria n. 1.823, a Política Nacional de Saúde do Trabalhador e da Trabalhadora (PNSTT) constituiu um dos principais avanços para a efetivação do direito à saúde do trabalhador. Tal política surge com o objetivo de orientar e articular as Barbarói, Santa Cruz do Sul, n. 57, p.<88-102>, jul./dez. 2020 
ações que já estavam sendo desenvolvidas para garantia desse direito, bem como as produções científicas da área (VASCONCELLOS; AGUIAR, 2017). Isso porque, a construção do campo da saúde do trabalhador e da trabalhadora, além de ser anterior a PNSTT, também precede a regulamentação constitucional desse direito (DIAS, 1994; MINAYO-GOMEZ, TEDIMCOSTA, 1997; MENDES, DIAS; 1991).

Quanto a positivação do direito fundamental à saúde do trabalhador no contexto brasileiro, enquanto marco normativo do Estado como um direito universal ${ }^{1}$, se deu com a Constituição Federal (CF) de $1988^{2}$, e, na legislação infraconstitucional, com a Lei Orgânica da Saúde nº 8080 de $1990^{3}$ (VASCONCELLOS, 2007). Todavia, observa-se que entre o período do qual esse direito foi firmado pela Carta Magna até a homologação, no ano de 2012 da PNSTT, tem-se um lapso de tempo com cerca de 24 anos. Tal fato se dá, porquanto, a saúde do trabalhador, enquanto um direito social (previsto no art. $6^{\circ}$ da $\mathrm{CF}$ ), não é considerada como um direito auto-aplicável (conforme o art. $5^{\circ}, \S 1^{\circ}$ da $\mathrm{CF}$ ), como o direito à vida, à liberdade, à igualdade, à segurança e à propriedade (art. $5^{\circ}$ da $\mathrm{CF}$ ), de modo que sua aplicação - e dos demais direitos sociais, ocorre de forma programática e progressiva (TOSI, 2005).

Assim, o período até a aprovação da PNSTT foi marcado por ações esparsas, sendo ora incorporado na vigilância, ora na assistência, ou em outras estruturas do Sistema Único de Saúde (SUS). Atualmente, essa política, além da Atenção Básica, incorpora a ação dos Centros

\footnotetext{
${ }^{1}$ A saúde do trabalhador trata-se de uma espécie do direito à saúde, e como tal, é de competência do Sistema Único de Saúde (SUS), a execução de ações nessa área (BRASIL, 2012). Salienta-se que, embora, a Previdência Social também abarque parte desse segmento, devido à sua lógica securitária e contributiva, apresenta-se como uma política seletiva aos trabalhadores integrantes do mercado de trabalho formal, regidos pela Consolidação das Leis do Trabalho (CLT), excluindo-se dessa proteção outras formas de labor, submetidas a vínculos distintos daquele (MENDES, et. al, 2015). Assim, para que se garanta a proteção à saúde dos trabalhadores e trabalhadoras, que abranja as distintas formas de labor do "precário mundo do trabalho" (ALVES, 2010), as ações de proteção e prevenção são desenvolvidas pelo SUS, afinal, este se trata de um sistema de acesso e de cobertura universal, conforme estabelecido pelo art. 196 da CF.

${ }^{2}$ Conforme "Art. 196. A saúde é direito de todos e dever do Estado, garantido mediante políticas sociais e econômicas que visem à redução do risco de doença e de outros agravos e ao acesso universal e igualitário às ações e serviços para sua promoção, proteção e recuperação" (BRASIL, 1988, s.p.). Além disso, no Brasil, o Direito à Proteção no Trabalho está previsto na $\mathrm{CF} / 88$ no Art. $6^{\circ}$ que estabelece como direitos sociais, dentre outros, a saúde e o trabalho, no Art. $7^{\circ}$ o qual dispõe que os direitos dos trabalhadores devem visar a melhoria de sua condição social, sendo que no inciso XXII aborda como uma das medidas a serem adotadas a "redução dos riscos inerentes ao trabalho, por meio de normas de saúde, higiene e segurança" (BRASIL, 1988, s.p.). Ademais, no Art. 200 determina-se que compete ao Sistema Único de Saúde, em seu inciso II a execução de "[...] ações de vigilância sanitária e epidemiológica, bem como as de saúde do trabalhador [...]” (BRASIL, 1988, s.p.) e no inciso VIII prevê a colaboração "[...] na proteção do meio ambiente, nele compreendido o do trabalho" (BRASIL, 1988, s.p.).

${ }^{3}$ No Art. $6^{\circ}, \S 3^{\circ}$, tem-se a regulamentação no plano legal e institucional do campo da ST, o qual estabelece que as ações desse campo, a serem executadas no SUS, devem contemplar questões de assistência, vigilância, informação, pesquisas e participação sindical (BRASIL, 1990). Outrossim, “a Lei estabelece também ser competência da instância federal do SUS participar da definição de normas, critérios e padrões para o controle das condições e dos ambientes de trabalho e coordenar a política de ST de forma hierarquizada e descentralizada para estados e municípios" (MINAYO-GOMEZ, VASCONCELLOS, MACHADO, 2018, p. 1965).
}

Barbarói, Santa Cruz do Sul, n. 57, p.<88-102>, jul./dez. 2020 
de Referência em Saúde do Trabalhador (Cerest), da Rede Nacional de Atenção Integral à Saúde do Trabalhador (Renast) e da Vigilância em Saúde do Trabalhador (Visat).

Entretanto, Ferreira (2015) ao observar o programa de assistência social para os casos de desaparecimento, analisou que por vezes a implementação de uma política, a partir de determinadas modalidades burocráticas, pode engendrar um processo duplo, produzindo por um lado, personagens sociais e por outro, estabelecendo um domínio de intervenção do Estado. É justamente a partir desse pressuposto teórico que se pretende analisar a PNSTT, tendo como base que a mesma influencia diretamente nos processos de saúde e doença da classe-que-vivedo-trabalho ${ }^{4}$.

Diante disso, este artigo está estruturado em dois momentos. No primeiro, serão descritos os principais pontos da trajetória das ações nesse campo, até a homologação da PNSTT. Salienta-se que se faz necessária a construção desse percurso já que, embora a mesma tenha unificado a atuação dos Cerest's, Renast e Visat, a criação destes é anterior a política.

Posteriormente, no segundo instante, será feita uma análise da PNSTT, a fim de compreender quem são os principais sujeitos a que se destina esse serviço, bem como verificar até que ponto o Estado pode intervir para que se assegure a proteção aos trabalhadores e trabalhadoras, atuando de forma preventiva, visando a redução dos adoecimentos e mortes ocasionados pela atividade laboral desempenhada pelo trabalhador.

\section{Breves notas sobre a Política Nacional de Saúde do Trabalhador e da Trabalhadora no Brasil}

De acordo com o que já foi assinalado, a construção do campo de saúde do trabalhador no contexto brasileiro é anterior a homologação da PNSTT de 2012, isso porque, desde o ano de 1991, o Ministério da Saúde buscava articular uma proposta que garantisse resultados efetivos. Nessa senda, menciona-se que a primeira proposta de Plano de Trabalho em Saúde do Trabalhador no SUS, teve como estratégia a criação dos Centros de Referência em Saúde do Trabalhador (Cerest) como alternativas para facilitar o diálogo com os sindicatos e capacitar os profissionais a fim de desenvolver as ações propostas (DIAS, HOEFEL, 2005).

\footnotetext{
${ }^{4}$ A expressão classe-que-vive-do-trabalho, de acordo com Antunes (2010) trata-se de uma noção ampliada de classe trabalhadora, que articula a dimensão do trabalho produtivo assalariado, com a dimensão do trabalho assalariado não produtivo. Incorpora tanto os(as) trabalhadores(as) produtivos, presentes na indústria, na agricultura e também no setor de serviços, privatizados pela lógica dominante do capital financeiro, como aqueles assalariados improdutivos, que não geram mais-valia, mas que são imprescindíveis no processo de trabalho capitalista e vivenciam situações que têm clara similitude com aquelas experimentadas pelos(as) trabalhadores(as) produtivos.
}

Barbarói, Santa Cruz do Sul, n. 57, p.<88-102>, jul./dez. 2020 
Já no ano de 1994, com a realização da II Conferência Nacional de Saúde do Trabalhador, teve-se discussões quanto a atuação do Ministério do Trabalho e da Saúde (DIAS, HOEFEL, 2005) bem como ratificou-se a determinação constitucional em municipalizar as ações (MINAYO-GOMEZ, VASCONCELLOS, MACHADO, 2018). Evidencia-se, nesse sentido que,

\begin{abstract}
Nos anos 90, a Área Técnica de Saúde do Trabalhador do Ministério da Saúde (COSAT) concentrou esforços em um amplo processo de capacitação técnica, para: ações de Vigilância e na Atenção Básica da Saúde; a elaboração de protocolos, normas e diretrizes, entre as quais, a Norma Operacional de Saúde do Trabalhador (NOST); a Lista de Doenças Relacionadas ao Trabalho e o Manual de Procedimentos para orientar as ações de Saúde do Trabalhador na rede de serviços de saúde, publicado em 2001; e o desenvolvimento de indicadores de saúde do trabalhador para o Sistema de Informação em Saúde, em especial a Rede Interagencial de Informações para a Saúde (RIPSA) (DIAS, HOEFEL, 2005, p. 820).
\end{abstract}

Posteriormente, ao final de 2002, a área técnica do Ministério da Saúde formula a proposta de criação de uma Rede Nacional de Atenção Integral à Saúde do Trabalhador (Renast), instituída pela Portaria No 1.679 de 2002 (DIAS, HOEFEL, 2005), que "em sua atual formatação institucional, prevista na Portaria $\mathrm{n}^{\circ} 2.728$, de 11 de novembro de 2009 , [...] deve integrar a rede de serviços do SUS por meio de Centros de Referência em Saúde do Trabalhador (Cerest)” (MINAYO-GOMEZ, VASCONCELLOS, MACHADO, 2018, p. 1966).

Contudo, dada a diversidade das ações no campo de Saúde do Trabalhador (ST) relativas a Renast, Cerest's, Visat e as produções acadêmicas, especialmente as desenvolvidas nas universidades públicas, incluídas a Fiocruz e a Fundacentro, necessitou-se buscar uma articulação mais orgânica entre os profissionais comprometidos com a melhoria das condições de trabalho e saúde dos trabalhadores.

Assim, no ano de 2012, é homologada a Política Nacional de Saúde do Trabalhador e da Trabalhadora (PNSTT), pela Portaria No 1.823 (BRASIL, 2012), que

Enquanto principal referência normativa de princípios e diretrizes da área de ST, a Política efetivamente pode contribuir, entre muitos outros aspectos, para superar o distanciamento entre a produção de conhecimentos de setores da academia e as necessidades de fundamentação na prática dos serviços (MINAYO-GOMEZ, VASCONCELLOS, MACHADO, 2018, p. 1967).

A PNSTT tem como finalidade, conforme disposto no Art. $2^{\circ}$, a definiçãa dos princípios, das diretrizes e as estratégias a serem observados pelas três esferas de gestão do Sistema Único de Saúde (SUS), para o desenvolvimento da atenção integral à saúde do trabalhador, com ênfase na vigilância, visando a promoção e a proteção da saúde dos trabalhadores e a redução da morbimortalidade decorrente dos modelos de desenvolvimento e dos processos produtivos (BRASIL, 2012). Dentre seus 16 artigos, subdivide-se em VI capítulos definindo princípios e 
diretrizes, objetivos, estratégias, responsabilidades, avaliação e monitoramento e financiamento, expressando em seu texto o compromisso em articular e viabilizar a atuação mais direcionada da Atenção Básica com a Visat, Cerest's e a Renast.

Todavia, mesmo após sua publicação, estudos como o de Costa et al (2013) mostram que muito ainda se tem a avançar no percurso de consolidação desse campo, porquanto a forma como o Estado tem regulado os conflitos entre o capital-trabalho tem se mostrado pouco efetivo. Tal fato se deve, pois, de acordo com Vasconcellos e Aguiar (2017, p. 606) o Brasil é “"...] alinhado com a ideologia liberal internacional de um capitalismo de mercado globalizado", logo, o país “[... ] tem dificuldades de implementar determinadas áreas na saúde, no caso da ST, que não sejam obedientes à ordem política e econômica vigente”.

Por essa razão é que se questiona até que ponto o Estado pode atuar para efetividade dessa política para a garantia do direito fundamental à saúde do trabalhador? Ainda, entendendo que as políticas são destinadas a seus usuários, quer-se compreender qual a universalidade que ela abarca, uma vez que de acordo com Tosi (2005) os direitos humanos (e como tal o direito a saúde do trabalhador) não são universais, nem tão pouco “universáveis", já que reproduzem constantemente a condição de excluídos/incluídos, dominantes/dominados e de emancipados/explorados.

Ademais, é preciso considerar, conforme Fonseca e Cardarello (1999), a noção de como os direitos humanos são traduzidos na prática, bem como as consequências para os seus titulares, as quais dependem das relações de poder forjadas em contextos históricos específicos. Assim, de acordo com as autoras, ao direcionar o olhar sobre determinada categoria, ou sujeitos de direitos, pode-se identificar que uns tem mais prioridade do que outros, reconhecendo também nesse processo, as lutas simbólicas e os critérios que determinam a reinvindicação e o acesso a população aos direitos, além de analisar, na sociedade, "[...] quem é mais, e que é menos, humano" (FONSECA, CARDARELLO, 1999, p. 83). É essa discussão que será utilizada como um norte no próximo tópico.

\section{PNSTT e a gestão da saúde e doença da classe-que-vive-do-trabalho}

Dentre os pontos que precisam ser destacados, o primeiro deles a ser mencionado são os usuários dessa política. Conforme estabelecido no art. $3^{\circ}$, a atenção da PNSTT é voltada para

Art. $3^{\text {o }}$ Todos os trabalhadores, homens e mulheres, independentemente de sua localização, urbana ou rural, de sua forma de inserção no mercado de trabalho, formal ou informal, de seu vínculo empregatício, público ou privado, assalariado, autônomo, avulso, temporário, cooperativados, aprendiz, estagiário, doméstico, aposentado ou desempregado [...]. (BRASIL, 2012, s.p.). 
A partir do disposto, verifica-se que qualquer trabalhador pode ser usuário dessa política em todos os níveis de atenção do SUS. Entretanto, mesmo que o seu acesso tenha caráter universal de atendimento, muitos dos casos de acidentes de trabalho não são relacionados as doenças laborais e nem sequer notificados. Isso porque, num levantamento realizado por Mendes et al (2015, p. 200), “constatou-se [...] que um dos principais desafios [no campo da saúde do trabalhador] está no reconhecimento e na identificação do usuário como trabalhador, uma vez que ele já é atendido no serviço [da Atenção Básica], mas destituído dessa identidade”.

Verifica-se, desse modo, a invisibilidade desse sujeito no SUS, pois não é reconhecido enquanto trabalhador, mas apenas como usuário do serviço. Nessa senda, Vasconcellos e Aguiar (2017, p. 209) asseveram que "a gestão do SUS usualmente atende a necessidades que dizem respeito aos efeitos dos problemas de saúde, e, não, às suas causas. O fato reproduz o modelo de saúde pré-constitucional, centrado na atenção à doença". Contudo, esse tipo de atendimento não está de acordo com o que estabelece o art. $6 \S 3^{\circ}$ da Lei 8.080/90, que além da recuperação e reabilitação da saúde, trabalha em termos de prevenção e proteção.

Ademais, em pesquisa feita por Moraes, Bertolozzi e Hino (2011), concluiu-se que

De modo geral, [...] os usuários buscam nos serviços de saúde respostas às queixas de ordem clínica. Não se revela [...] uma conexão imediata entre as necessidades de saúde e a peculiaridade de sua inserção na sociedade. Isto porque, tradicionalmente, as pessoas compreendem mais concretamente a dimensão biológica do processo saúdedoença e não associam às questões sociais que atuam de forma a fortalecer ou desgastar o processo de vida. (MORAES; BERTOLOZZI; HINO, 2011, P. 22).

Assim, verifica-se que tanto na concepção dos usuários, como no atendimento desses pelos profissionais, as ações desenvolvidas têm sido voltadas para uma lógica clientelista, invisibilizando o processo de saúde-doença e trabalho - que deveria se constituir enquanto objeto de ação. Logo, aduzem Mendes et al. (2015, p. 204) que "a falta de correlação por parte dos profissionais de saúde, muitos imersos na lógica de programas verticalizados em saúde, fragmentados em população-alvo, [...] acabam deixando de fora todo o restante da população que não se encaixa no perfil [...]".

Acerca do perfil dos usuários, Vieira (2014, p. 15) analisa que quando se fala em

[...] meio ambiente de trabalho saudável e seguro, vem-nos à mente a busca pela proteção da força de trabalho dos riscos de acidentes graves, por exemplo, na construção civil, em minas e garimpos ou em indústrias pesadas, isto é, pensamos em trabalhadores do sexo masculino exercendo "trabalho pesado". Não vinculamos os riscos laborais às mulheres ou às profissões geralmente relacionadas a elas, como serviços de saúde, de educação e o trabalho doméstico. 
Isso se deve ao fato que o trabalho feminino e os riscos a ele inerentes na maioria das situações são tratados como invisíveis, porquanto o foco majoritariamente da área são os grupos masculinos. A essa invisibilidade, Vieira (2014) atribui ao fato da submissão das mulheres as definições universais, que sob o manto dos direitos humanos desconsideram e mascaram as reais desigualdades existentes em nossa sociedade.

Tal situação ocorre, pois, embora na atualidade a concepção de direitos humanos remeta à ideia de acesso universal às condições mínimas de dignidade da pessoa humana, independentemente de qualquer discriminação, em sua origem, essas conceituações detinham conotação diversa, uma vez que a "Declaração dos Direitos do Homem e do Cidadão" de 1789, ao proclamar que "os homens nascem e permanecem livres e iguais em direitos", objetivava salvaguardar as liberdades individuais e garantir o direito de participação na vida pública (FONSECA, 1999). Contudo, esse espaço público era estritamente masculino, excluindo-se dele as crianças, aqueles sem propriedade, os escravos, os negros livres, algumas minorias religiosas e, as mulheres (HUNT, 2009).

Desta forma, embora muito se tem avançado para desmistificar esse conceito generalista e dar visibilidade a outras categorias que precisam de atenção na área da ST, dada a falta de reconhecimento da relação entre saúde/doença com a atividade laboral desempenhada, inúmeros adoecimentos e mortes no trabalho permanecem invisíveis, principalmente quando relacionados a trabalhos de mulheres, de imigrantes, de negros, de terceirizados, de vínculos informais, etc. Logo, assinalam Mendes et al (2015, p. 205) que:

\footnotetext{
O aprofundamento das ações em saúde do trabalhador será possível quando for atribuída visibilidade aos agravos, através de condições para sua correta notificação e da garantia da longitudinalidade da atenção. Afinal, o agravo, quando reconhecido, só é notificado em situações excepcionalmente graves, deixando-se de lado os demais impactos e doenças que se instalam, lenta e silenciosamente, ao longo de todo o processo.
}

Ademais, a falta de dados reais acerca dos adoecimentos e mortes laborais limita um diagnóstico preciso que possa fundamentar ações de promoção e prevenção da saúde no âmbito dos Cerest's, Renast's e da Visat. Nessa senda, observam Costa et al (2013) que a Previdência Social, embora restrita aos trabalhadores que dela contribuem, detém um banco de dados com informações epidemiológicas dos benefícios, fundamentais para delinear estratégias na área, porém esses dados são omitidos e tratados como segredo fiscal pela instituição.

Também, de acordo com Costa et al (2013), outro fator limitante da atuação do SUS com ações mais efetivas deve-se ao fato que na Política Nacional de Segurança e Saúde no Trabalho, estabelecida pelo Decreto $\mathrm{N}^{\circ} 7.602$, de 7 de novembro de 2011, destinou ao até então 
Ministério do Trabalho e Emprego ${ }^{5}$ às ações de Vigilância dos processos de trabalho ${ }^{6}$, enquanto ao Ministério da Saúde restou a posição de "fortalecimento das ações de vigilância" ", anulando, em certa medida, um desempenho mais efetivo desse último.

Portanto, apesar de todo o marco regulatório, percebe-se a desconexão de informações e de atuação das áreas no campo da saúde do trabalhador. Esse “[...] desconhecimento da dimensão do impacto do trabalho na saúde dos trabalhadores afeta diretamente os serviços pesquisados" (MENDES et al, 2015, p. 204), além de limitar a ação do Estado.

Também, conforme Vasconcellos e Aguiar (2017, p. 606), acerca do alcance da atuação do Estado para a efetivação da PNSTT, deve-se considerar a "[...] contradição de o SUS ser uma política de bem-estar social abrigada em um Estado de 'bem-estar do mercado"” que coloca a mesma "[...] no centro de um debate político-normativo e epistemológico que se justifica pelo enorme impacto do adoecimento e morte no trabalho que a saúde pública ainda não dimensionou acuradamente e não enfrenta cotidianamente".

Destarte, esses fatores acima citados implicam na atenção dos usuários, de modo que uns trabalhadores, principalmente os que contribuem com a Previdência Social, detém uma assistência maior com relação as doenças laborais, porquanto através do Nexo Técnico Epidemiológico, o adoecimento e morte é relacionado com a atividade laboral desempenhada.

Catalogar essas doenças é fundamental para que se exija dos empregadores ações de prevenção e proteção. Porém, reconhecer essas doenças obriga as empresas a adotarem medidas para redução de riscos, sendo na maioria das vezes oneroso fazê-las. Assim, dentro de uma lógica do estado capitalista, a qual se volta para atender aos interesses de mercado, é deveras interessante que se mantenham invisíveis as variadas formas de adoecimento e morte da classeque-vive-do-trabalho.

A partir disso verifica-se que a PNSTT, ao fazer a gestão da saúde/doença, com um caráter clientelista, não resolve o real problema dos adoecimentos e mortes no trabalho, sendo apenas uma medida curativa até que o trabalhador volte na empresa e torne a adoecer, passando para descartável quando não conseguir mais ter forças para realizar seu serviço.

\footnotetext{
${ }^{5}$ Extinto em outubro de 2015, sendo atualmente, no governo de Jair Bolsonaro, uma Secretaria Especial de Previdência e Trabalho do Ministério da Economia.

6"VI - Cabe ao Ministério do Trabalho e Emprego: a) formular e propor as diretrizes da inspeção do trabalho, bem como supervisionar e coordenar a execução das atividades relacionadas com a inspeção dos ambientes de trabalho e respectivas condições de trabalho" (BRASIL, 2011, s. p.).

7“"Cabe ao Ministério da Saúde: a) fomentar a estruturação da atenção integral à saúde dos trabalhadores, envolvendo a promoção de ambientes e processos de trabalho saudáveis, o fortalecimento da vigilância de ambientes, processos e agravos relacionados ao trabalho, a assistência integral à saúde dos trabalhadores, reabilitação física e psicossocial e a adequação e ampliação da capacidade institucional” (BRASIL, 2011, s. p.).
}

Barbarói, Santa Cruz do Sul, n. 57, p.<88-102>, jul./dez. 2020 
Com base nessa discussão, importa mencionar as categorias da biopolítica, de Michel Foucault, e da necropolítica, de Achille Mbembe. Segundo Foucault, a biopolítica, atua sobre o homem-espécie, afetando o conjunto de "[...] processos que são próprios da vida, como o nascimento, a morte, a produção, a doença, etc.” (FOUCAULT, 1999, p. 289), ademais, congrega uma série de

[...] fenômenos que se começa a levar em conta no final do século XVIII e que trazem a introdução de uma medicina que vai ter, agora, a função de uma higiene pública, com organismos de coordenação dos tratamentos médicos, de centralização da informação, de normalização do saber, e que adquire também o aspecto de campanha de aprendizado da higiene e de medicalização da população. Portanto, problemas da reprodução, da natalidade, problemas da morbidade também. $\mathrm{O}$ outro campo de intervenção da biopolítica vai ser todo um conjunto de fenômenos dos quais uns são universais e outros são acidentais, mas que, de uma parte, nunca são inteiramente compreensíveis, mesmo que sejam acidentais, e que acarretam também consequências análogas de incapacidade, de pôr indivíduos fora de circuito, de neutralização, etc. Será o problema muito importante, já no início do século XIX (na hora da industrialização), da velhice, do indivíduo que cai, em consequência, para fora do campo de capacidade, de atividade. E, da outra parte, os acidentes, as enfermidades, as anomalias diversas. É em relação a estes fenômenos que essa biopolítica vai introduzir não somente instituições de assistência (que existem faz muito tempo), mas mecanismos muito mais sutis, economicamente muito mais racionais do que a grande assistência, a um só tempo maciça e lacunar, que era essencialmente vinculada à Igreja. Vamos ter mecanismos mais sutis, mais racionais, de seguros, de poupança individual e coletiva, de seguridade, etc. (FOUCAULT, 1999, p. 291).

Logo, é a biopolítica que garante a inserção controlada dos corpos no aparelho de produção, ajustando, consequentemente, não somente os corpos disciplinados, mas também a população aos processos econômicos (HILÁRIO, 2016). Isso ocorre, pois, se tratando de um problema político, a população é o terreno no qual a biopolítica vai regulamentar a vida e disciplinar o corpo, modificando assim o poder político para o direito de fazer viver e deixar morrer: um poder que, ao mesmo tempo em que se esforça no prolongamento e multiplicação de vidas, também pode matar e deixar morrer.

Por sua vez, se aplicada a área da ST, entende-se que por um lado tem-se o esforço em relação ao prolongamento da vida dos sujeitos, e por outro, também pode resultar no adoecimento e morte dos trabalhadores ao não dar a devida visibilidade aos processos de saúdedoença/morte e sua relação com a atividade laboral desempenhada.

Portanto, a biopolítica ao mesmo tempo que trata sobre a gestão da vida, ela produz a gestão da morte, porquanto, para regular a vida e sua produtividade, é necessário que outros sejam alvo de uma série de precarizações que resultam no adoecimento e até na morte. Esse processo, pode ser analisado, ainda, como a passagem da biopolítica para a necropolítica, uma vez que, não se tem mais uma política voltada para a produção da vida, mas sim, para a aniquilação da classe trabalhadora em larga escala através da superexploração do trabalho. 
Acerca dessa transição da biopolítica para a necropolítica, observa Hilário (2016, p. 203) que não se têm mais

[...] uma política voltada para a produção de vida - ainda que adequada à forma social, [...] - e sim uma política cujo objetivo é a aniquilação em larga escala. Aqui a tendência para o 'trabalho morto' na produção de valor encontra o 'trabalho de morte' da política. Os indivíduos começam a sobrar diante da forma social atual, pois já não são mais rentáveis, não são mais requisitados a dispenderem sua força de trabalho no interior do processo produtivo amplo. Muito pelo contrário, são expulsos e jogados no mercado informal e precário, nas margens da cidade etc. (HILÁRIO, 2016, p. 203).

Portanto, verifica-se que as massas de trabalhadores, considerados supérfluos, passam a viver em um estado de precariedade, pois o sistema econômico-social não tem lugar para todos. Essas pessoas passam a ocupar as bordas do mundo social, com condições precárias de vida ou mesmo em situação de sobrevida. Esses corpos, considerados sobrantes ao sistema, não mais necessários para a reprodução do capital, “[...] são submetidos a condições de vida que lhes conferem o status de "mortos-vivos"” (MBEMBE, 2016, p. 146), afinal, são portadores de vidas descartáveis.

Essa realidade se faz presente em países latino-americanos, como o Brasil, onde a ordem democrática e a colonial estão conectadas. A democracia e o "[...] império colonial fazem objetivamente parte de uma mesma matriz histórica. Este fato originário e estruturante é central a qualquer compreensão histórica da violência da ordem mundial contemporânea" (MBEMBE, 2017, p. 43).

Observa-se, então, que a necropolítica (essa subsunção da vida ao poder da morte) se constitui como categoria fundamental para se pensar a realidade de países colonizados, principalmente, para entender que se as tecnologias de extermínio e exclusão possuem alvos racialmente marcados, também atingem, com intensidades diferentes, as populações nãonegras, também cada vez mais precarizadas (LIMA, 2018), ou seja, a classe-que-vive-dotrabalho como um todo.

Portanto, ao trazer essa discussão para uma leitura da PNSTT verifica-se que, ao invisibilizar a relação entre saúde-doença/morte com o trabalho, ao invés de produzir um "trabalho de vida", com pessoas sadias para a produção de riquezas, tem-se um "trabalho de morte", com sujeitos considerados supérfluos e desnecessários, onde na medida que adoecem e morrem são substituídos e descartados - passando a viver num estado de precariedade. Logo, mesmo que a PNSTT seja uma política contra-hegemônica, pois busca ir contra os limites de exploração da classe trabalhadora, sua atuação é deveras limitada, afinal a desarticulação de ações, além da falta do computo dos dados necessários para um diagnóstico mais preciso da realidade, impede que se tenha uma real intervenção na sociedade com medidas voltadas para 
a promoção e prevenção da saúde, uma vez que conforme a Organização Mundial da Saúde (OMS, 2006), a saúde não é apenas a ausência de doenças, mas sim o completo bem-estar físico, mental e social.

\section{Considerações Finais}

Diante do exposto, fica patente a lacuna existente entre as ações do SUS e a efetividade na prevenção e promoção da saúde do trabalhador. Conforme visto, o usuário dos serviços ainda é atendido através de uma lógica clientelista, com foco apenas no tratamento, sendo que sua doença somente é relacionada ao processo de trabalho quando for algo extremamente grave. Desse modo, são invisibilizados os reais condicionantes da saúde-doença no labor, e, por conseguinte, não são desenvolvidas atividades que realmente podem contribuir na efetiva melhora da qualidade de vida dos trabalhadores.

Também, com as reflexões, identificou-se que a saúde e segurança no trabalho, bem como a área ST, ainda tem foco predominantemente voltado para as relações de trabalho formais, com profissões masculinas. Com a figura desse tipo de personagem social a que se destina a política, muitos trabalhadores informais, terceirizados, avulsos, imigrantes, mulheres dentre outros, por entenderem que não se enquadram naquele perfil, deixam de comunicar os agravos relacionados a suas atividades, resultando num diagnóstico impreciso do mercado de trabalho. Muito se tem avançado nessas discussões, mas o caminho a ser percorrido ainda é longo.

Por fim, em relação ao domínio de intervenção do Estado, pode-se concluir que a atuação deste é voltada principalmente aos interesses do mercado, de modo que fragmentar as ações no campo da ST entre a Previdência Social, o Ministério da Saúde e a atual Secretaria Especial de Previdência e Trabalho do Ministério da Economia, ao mesmo tempo que amplia a área de atuação, acaba dissipando os principais pontos de intervenção. Logo, não se alteram efetivamente as relações entre os proprietários dos meios de produção com os trabalhadores, ocultando o processo de adoecimento e morte no trabalho.

Portanto, pode-se concluir que o desempenho estatal é voltado muito mais para a necropolitica, do que para a biopolítica, afinal, ao tratar apenas do adoecimento dos usuários, sem considera-los como trabalhadores, se encobre todo um debate a ser feito acerca das relações entre o capital e o trabalho. Com isso mantém-se a lógica de obtenção de cada vez mais lucros por parte das empresas, pela exploração do trabalhador, sendo que este além de submetido a modalidades de labor precárias, quando doente - devido a atividade desempenhada, é demitido, 
e porque não falar descartado, permanecendo relegado ao desemprego por não ser considerado saudável. Desse modo, embora a PNSTT seja uma política contra hegemônica, ainda tem um percurso a trilhar afim de que sejam desenvolvidas medidas que possam assegurar o direito a saúde do trabalhador, em seu completo mais completo bem-estar.

\title{
NATIONAL POLICY ON WORKER HEALTH AND WORKER: A REFLECTION ON THE MANAGEMENT OF HEALTH AND ILLNESS OF THE WORKING-CLASS
}

\begin{abstract}
It seeks to carry out a discussion about the National Policy for Workers' Health (PNSTT), in the Brazilian context, based on a reflection on the health and illness process of the workingclass. Therefore, it is based on the theoretical assumption that a policy, when outlined and implemented, can result in a double process, producing, on the one hand, social characters and, on the other, establishing a domain of State intervention. From the analysis carried out, it was found that, within the scope of the Unified Health System, the work is focused only on the treatment of illnesses, making workers invisible, thus failing to relate the work process with illness. Furthermore, it was identified that although it is a policy with broad attention to workers, in the social imaginary, it has as a character the worker inserted in the formal market, who performs risky activities related to "heavy work". Regarding the limits of the State's performance, it can be observed that, acting only with treatment measures, the promotion and prevention of ST is not ensured. This performance, in turn, leads us to conclude that the focus of state attention seems to be directed, primarily, to the economic interests of capital.

Keywords: National Health Policy for Workers. Class-that-lives-from-work. Health Unic System.
\end{abstract}

\section{REFERÊNCIAS}

ALVES, Giovanni. O novo (e precário) mundo do trabalho: reestruturação produtiva e crise do sindicalismo. São Paulo: Boitempo, 2010.

ANTUNES, Ricardo. Os sentidos do trabalho: ensaio sobre a afirmação e a negação do trabalho. São Paulo: Boitempo, 2010.

BRASIL. Ministério da Saúde. Portaria $\mathbf{N}^{\mathbf{0}}$ 1.823, de 23 de agosto de 2012. Institui a Política Nacional de Saúde do Trabalhador e da Trabalhadora. Brasília (DF), 2012. Disponível em: http://bvsms.saude.gov.br/bvs/saudelegis/gm/2012/prt1823_23_08_2012.html. Acesso em: 10 mar. 2020.

Decreto $N^{\circ}$ 7.602, de 7 de novembro de 2011.Dispõe sobre a Política Nacional de Segurança e Saúde no Trabalho - PNSST. Brasília (DF), 2011. Disponível em: http://www.planalto.gov.br/ccivil_03/_ato2011-2014/2011/decreto/d7602.htm. Acesso em: 10 mar. 2020.

Lei $N^{\circ}$ 8.080, de 19 de setembro de 1990. Dispõe sobre as condições para a promoção, proteção e recuperação da saúde, a organização e o funcionamento dos serviços correspondentes e dá outras providências. Brasília (DF): Presidência da República, 1990. 
. [Constituição (1988)]. Constituição da República Federativa do Brasil de 1988.

Brasília (DF): Presidência da República, [2019].

COSTA, Danilo et al. Saúde do Trabalhador no SUS: desafios para uma política pública. Rev. bras. saúde ocup., São Paulo, v. 38, n. 127, p. 11-21, jun. 2013. Disponível em:

$<$ http://www.scielo.br/scielo.php?script=sci_arttext\&pid=S0303-

$76572013000100003 \& \operatorname{lng}=e n \& n r m=i s o>$. Acesso em: 10 mar. 2020.

DIAS, Elizabeth Costa. HOEFEL, Maria da Graça. O desafio de implementar as ações de saúde do trabalhador no SUS: a estratégia da RENAST. Ciênc. saúde coletiva, Rio de Janeiro, vol. 10, n. 4, p. 817-827, 2005. Disponível em:

http://www.scielo.br/scielo.php?pid=S1413-

$81232005000400007 \&$ script=sci_abstract\&tlng=pt. Acesso em: 10 mar. 2020.

. A Atenção à Saúde dos Trabalhadores no Setor Saúde (SUS) no Brasil:

Realidade, Fantasia ou Utopia? 1994. 350 f. Tese, Programa de Pós-Graduação em Saúde Coletiva. Faculdade de Ciências Médicas. UNICAMP. Campinas.

FERREIRA, Letícia. Formalidades, moralidades e disputas de papel: a administração de casos de crianças desaparecidas no Rio de Janeiro. Dilemas: Revista de Estudos de Conflito e Controle Social, v. 8, n. 2, 2015.

FONSECA, Claúdia; CARDARELLO, Andréa. Direitos dos mais e dos menos humanos. Horizontes Antropológicos, n. 10, Porto Alegre: UFRGS, 1999, p. 83-121.

FONSECA, Rosa Maria Godoy Serpa da. MULHER, DIREITO E SAÚDE: repensando o nexo coesivo. Saúde e Sociedade, São Paulo, v. 8, n. 2, p. 03-32, 1999. Disponível em: http://www.scielo.br/scielo.php?pid=S010412901999000200002\&script=sci_abstract\&tlng=pt. Acesso em: 20 fev. 2020.

FOUCAULT, Michel. Em defesa da sociedade: curso no Collège de France (1975-1976). São Paulo: Martins Fonte, 1999.

HILÁRIO, Leomir Cardoso. Da biopolítica à necropolítica: variações foucaultianas na periferia do capitalismo. Sapere Aude, Minas Gerais, v. 7, n. 12, p. 194-210, jan./jun. 2016. DOI: https://doi.org/10.5752/P.2177-6342.2016v7n13p194. Disponível em: http://periodicos.pucminas.br/index.php/SapereAude/article/view/11813. Acesso em: 20 ago. 2020.

HUNT, Lyn. A Invenção dos Direitos Humanos: uma história. São Paulo: Companhia das Letras, 2009.

LIMA, Fátima. Bio-necropolítica: diálogos entre Michel Foucault e Achille Mbembe. Arq. bras. psicol., Rio de Janeiro, v. 70, n. spe, p. 20-33, 2018. Disponível em: http://pepsic.bvsalud.org/scielo.php?script=sci_arttext\&pid=S180952672018000400003\&lng=pt\&nrm=iso. Acessos em: 24 ago. 2020.

MBEMBE, Achille. Políticas de Inimizade. Lisboa: Antígona, 2017. 
. Necropolítica. Arte \& Ensaios, Rio de Janeiro, n. 32, p. 123-152, 2016. Disponível em: https://revistas.ufrj.br/index.php/ae/article/view/8993. Acesso em: 20 set. 2019.

MENDES, Jussara Maria Rosa, et al. Saúde do trabalhador: desafios na efetivação do direito à saúde. Argumentum, v. 7, n. 2, p. 194-207, 23 dez. 2015. DOI:

https://doi.org/10.18315/argumentum.v7i2.10349. Disponível em:

http://periodicos.ufes.br/argumentum/article/view/10349. Acesso em: 10 mar. 2020.

MENDES, René; DIAS, Elizabeth Costa. Da Medicina do Trabalho à Saúde do Trabalhador. Revista de Saúde Pública, São Paulo, vol. 25, n. 5, 1991. Disponível em: http://www.scielo.br/pdf/rsp/v25n5/03.pdf. Acesso em: 04 mar. 2020.

MINAYO-GOMEZ, Carlos; THEDIM-COSTA, Sônia Maria da Fonseca. A Construção do Campo da Saúde do Trabalhador: Percurso e Dilemas. Cadernos de Saúde Pública, Rio de Janeiro, n. 13, supl. 2, 1997. p. 21-32. Disponível em:

http://www.scielo.br/pdf/csp/v13s2/1361.pdf. Acesso em: 04 mar. 2020.

; VASCONCELLOS, Luiz Carlos Fadel de; MACHADO, Jorge Mesquita Huet. Saúde do trabalhador: aspectos históricos, avanços e desafios no Sistema Único de Saúde. Ciênc.

Saúde coletiva, Rio de Janeiro, vol. 23, n. 6, jun. 2018. Disponível em:

http://www.scielo.br/scielo.php?script=sci_arttext\&pid=S1413-

81232018000601963\&lng=pt\&nrm=iso\&tlng=pt. Acesso em: 10 mar. 2020.

MORAES, Paulo Alexandre de; BERTOLOZZI, Maria Rita; HINO, Paula. Percepções sobre necessidades de saúde na Atenção Básica segundo usuários de um serviço de saúde. Revista Escola Enfermagem USP, São Paulo, n. 45, v. 1, p. 19-25, 2011. Disponível em:

<http://www.scielo.br/pdf/reeusp/v45n1/03.pdf>. Acesso em: 10 mar. 2020.

ORGANIZAÇÃO MUNDIAL DA SAÚDE. Constituição da Organização Mundial da

Saúde. Documentos básicos, suplemento da 45ª edição, outubro de 2006. Disponível em espanhol em: https://www.who.int/governance/eb/who_constitution_sp.pdf. esso em: 10 mar. 2020 .

TOSI, Guiuseppe. Os direitos humanos: reflexões iniciais. In: TOSI, Guiuseppe (org.).

Direitos Humanos: história, teoria e prática. João Pessoa: Editora Universitária, 2005. p. 1847.

VASCONCELLOS, Luiz Carlos Fadel de; AGUIAR, Luciene. Saúde do Trabalhador: necessidades desconsideradas pela gestão do Sistema Único de Saúde. Saúde debate, Rio de Janeiro, v. 41, n. 113, p. 605-617, abr. 2017 . Disponível em:

<http://www.scielo.br/scielo.php?script=sci_arttext\&pid=S0103-

11042017000200605\&lng=en\&nrm=iso>. Acesso em: 10 mar. 2020.

. Saúde, trabalho e desenvolvimento sustentável: apontamentos para uma política de Estado. 2007. Tese (Doutorado em Saúde Pública) - Escola Nacional de Saúde Pública, Rio de Janeiro: 2007.

VIEIRA, Regina Stela Corrêa. Saúde e Segurança no Trabalho das Mulheres: a perspectiva de gênero para a proteção e promoção do meio ambiente laboral equilibrado. 
Dissertação (Mestrado em Direito) - Faculdade de Direito, Universidade de São Paulo, São Paulo, 2014.

Data de recebimento: $26 / 04 / 2020$

Data de aceite: $18 / 08 / 2020$

\section{Sobre os autores:}

Maritânia Salete Salvi Rafagnin é Doutoranda em Política Social e Direitos Humanos e Mestra em Política Social pela Universidade Católica de Pelotas. Bolsista CAPES. Endereço Eletrônico: mari.salvi@gmail.com

Thiago Ribeiro Rafagnin é Pró-Reitor de Gestão de Pessoas e Docente do Curso de Direito da Universidade Federal do Oeste da Bahia, na vaga de Direito Constitucional. Doutor em Política Social e Direitos Humanos pelo PPGPSDH/UCPel. Endereço Eletrônico: rafagnin40@hotmail.com 